\title{
Frações de carbono e nitrogênio de um Latossolo Vermelho-Amarelo distrófico sob diferentes usos na Amazônia brasileira
}

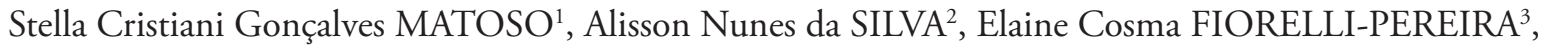 \\ Queicianne Paniago COLLETA ${ }^{4}$, Emanuel MAIA ${ }^{5}$
}

\begin{abstract}
RESUMO
O objetivo deste estudo foi avaliar indicadores de qualidade de um Latossolo Vermelho-Amarelo distrófico sob vegetação nativa de floresta, pastagem (Brachiaria brizantha cv. marandu), plantio convencional, cultivo mínimo e sistema de plantio direto. Foram determinados o carbono e o nitrogênio da biomassa microbiana do solo, o carbono orgânico e o nitrogênio total do solo, quocientes microbianos para carbono e nitrogênio e relaçóes entre carbono orgânico e nitrogênio total do solo $(\mathrm{C} / \mathrm{N}$ tot $)$ e entre carbono e nitrogênio da biomassa microbiana $(\mathrm{C} / \mathrm{N}$ mic). As amostras foram coletadas em Cerejeiras/RO, em duas profundidades $(0-10$ e 10-20 cm) nos cinco tratamentos, com cinco repetiçóes. A análise estatística consistiu na análise de dados discrepantes, pelo método de Chauvenet, e dos pressupostos das variâncias, pelo teste de Bartlett e de Shapiro-Wilk, seguidos do teste de Kruskal-Wallis, entre os tratamentos, e comparaçáo das variáveis entre as profundidades, pelo teste de Mann-Whitney, e ainda da análise de agrupamentos utilizando o método de Ward, todos ao nível de 5\% de probabilidade. Os diferentes usos do solo influenciam as variáveis avaliadas, com exceçáo da relaçáo $\mathrm{C} / \mathrm{N}$ tot, sendo que as variáveis microbiológicas demonstram-se mais sensíveis às mudanças do uso e manejo do solo. O sistema de plantio convencional é o tratamento que apresenta maior homogeneidade entre as profundidades. A análise de agrupamentos evidencia que o solo sob plantio direto, sistema de cultivo mínimo e plantio convencional apresenta semelhanças entre si, assim como, o solo sob vegetaçáo nativa de floresta e pastagem também se assemelham.
\end{abstract}

PALAVRAS-CHAVE: biomassa microbiana do solo, indicadores de qualidade, sistemas de cultivo.

\section{Carbon and nitrogen fractions in a dystrophic Red Yellow Latosol (Oxisol) soil under different uses in the Brazilian Amazon}

\begin{abstract}
The aim of this study was to assess quality indicators of a dystrophic Red Yellow Latosol (Oxisol) soil under native forest, pasture (Brachiaria brizantha cv. marandu), conventional tillage, minimum tillage system and no till system. It was determined the soil carbon and soil nitrogen in the microbial biomass, organic carbon and total nitrogen, ratios for microbial carbon and nitrogen and relationships between organic carbon and total nitrogen $(\mathrm{C} / \mathrm{N}$ tot $)$ and between carbon and soil nitrogen in the microbial biomass (C/N mic). The soil samples were collected in the Municipality of Cerejeiras/RO, at two depths (0-10 and 10-20 $\mathrm{cm}$ ) in five treatments with five replications. The statistical analysis consisted of outliers analysis by Chauvenet method, and assumptions of variances by Bartlett's test and Shapiro-Wilk, followed by Kruskal-Wallis, between treatments, and comparison the variables between the depths, by Mann-Whitney' test, and the group analysis using Ward's method, all at 5\% probability. The results show that different uses influence the variables, except for ration $\mathrm{C} / \mathrm{N}$ tot, and the microbiology variables showed themselves more sensitive to changes in land use and management than other. The conventional tillage is the treatment that has greater homogeneity among the depths. The group analysis shows that the soil under no till system, minimum tillage system and conventional tillage have similarities among well as the soil under native forest and pasture are similar.
\end{abstract}

KEYWORDS: soil microbial biomass, soil quality indicators, crop systems.

\footnotetext{
${ }_{1}^{1}$ Rua Rio Grande do Sul, no 4386, Bairro Centro, Colorado do Oeste/R0, 76993-000. stella.matoso@ifro.edu.br;

2 Av. Noroeste, $n^{0}$ 523, quadra w13, casa 17, CJ Tucumã I - Bairro Distrito industrial, Rio Branco/AC, 69917-400. floydwatters@hotmail.com;

${ }^{3}$ Av. Norte Sul, nº 7300, Bairro Nova Morada, Rolim de Moura/R0, 76940-000. elainefiorelli@yahoo.com;

${ }^{4}$ Rua Guararapes, $n^{0}$ 649, Bairro Seringal, Pimenta Bueno/R0, 76970-000. queicy_paniago@hotmail.com;

${ }^{5}$ Av. Norte Sul, $n^{0} 7300$, Bairro Nova Morada, Rolim de Moura/R0, 76940-000. emanuel@unir.br
} 


\section{INTRODUÇÃO}

O conceito de qualidade do solo começou a ser formulado no início dos anos 90, sendo definido, de forma simplificada, como a aptidáo para o uso agrícola. Com o passar dos anos e a evolução das pesquisas este conceito foi incrementado, e um solo de qualidade é definido como aquele capaz de funcionar dentro dos limites de um ecossistema, sustentando a produtividade biológica, mantendo a qualidade do ambiente e promovendo a saúde de plantas e animais (Conceição et al. 2005).

A necessidade de estudar o solo nos seus aspectos qualitativos cresceu junto com o aumento de seu uso, que deve ser avaliado a partir de indicadores de qualidade eficientes, que segundo Doran e Zeiss (2000) são aqueles sensíveis às variaçōes do manejo, capazes de elucidar os processos do ecossistema, compreensíveis e úteis ao agricultor e, preferentemente, de fácil e barata mensuração.

Neste contexto a matéria orgânica é o principal indicador de qualidade do solo, pois está diretamente relacionada às características físicas, químicas e biológicas do solo. Porém, como afirma Souza (2005) sua resposta às técnicas de manejo e uso do solo é lenta, podendo não ser perceptível por décadas, diferente da biomassa microbiana do solo, que possui respostas mais rápidas, expressando alterações causadas pelo manejo empregado. Desta forma a biomassa microbiana é um importante indicador de qualidade, pois qualquer estresse no sistema afetará a densidade, a diversidade e a atividade das populaçôes microbianas (Ferreira et al. 2007). Souza (2005) menciona que no estudo da dinâmica da matéria orgânica, para se entender os efeitos dos diferentes manejos do solo, as determinaçôes do carbono orgânico total do solo e carbono da biomassa microbiana são imprescindíveis e não devem ser analisadas separadamente.

O nitrogênio $(\mathrm{N})$, por sua vez, ocupa posição de destaque entre os elementos essenciais ao desenvolvimento das plantas. A grande necessidade deste, pelos vegetais faz com que seja um dos nutrientes mais limitantes à produtividade da maioria dos sistemas agrícolas (Reis et al. 2006). O N é um dos elementos mais sensíveis às modificaçôes das condições ambientais, como consequência dos inúmeros processos químicos e biológicos que controlam a sua disponibilidade e perda (Maluche 2004).

A biomassa microbiana do solo compreende fonte potencial de $\mathrm{N}$ para as plantas, bem como de outros nutrientes e os fluxos através do reservatório microbiano são de particular relevância no solo (Barreto et al. 2008). O nitrogênio da biomassa microbiana indica o potencial de reserva do $\mathrm{N}$, quanto maior o compartimento do nitrogênio da biomassa microbiana, menores serão as perdas do $\mathrm{N}$ no sistema, e maior a fração lábil da matéria orgânica prontamente disponível no solo e potencialmente utilizada para as plantas (Souza 2005).

A partir da quantificaçáo do carbono orgânico total, carbono da biomassa microbiana, nitrogênio total do solo e nitrogênio da biomassa microbiana é possível determinar o quociente microbiano, tanto para $\mathrm{C}$ (qMiC), quanto para $\mathrm{N}$ (qMiN) (Anderson e Domsch 1989). Para Wardle (1994) este quociente pode avaliar a qualidade da matéria orgânica, enquanto para Ferreira (2008) trata-se de um indicador da dinâmica da mesma, expressando a eficiência da biomassa em utilizar $\mathrm{C}$ e $\mathrm{N}$.

Ainda são escassos estudos de indicadores de qualidade do solo na regiáo amazônica envolvendo fraçôes de $\mathrm{Ne} \mathrm{C}$, e como nas últimas décadas ocorreu um grande aumento nas atividades agrícolas nesta regiáo tornam-se interessantes e necessárias pesquisas deste cunho.

O objetivo deste trabalho foi avaliar indicadores de qualidade do solo, a partir da determinaçáo do carbono da biomassa microbiana, nitrogênio da biomassa microbiana, carbono orgânico total, nitrogênio total do solo, qMiC e qMiN, e relaçôes entre o carbono orgânico total e nitrogênio total do solo ( $\mathrm{C} / \mathrm{N}$ tot) e entre o carbono da biomassa microbiana e nitrogênio da biomassa microbiana ( $\mathrm{C} / \mathrm{N} \mathrm{mic})$, em cinco diferentes usos: plantio convencional, cultivo mínimo, plantio direto, pastagem e vegetação nativa de floresta.

\section{MATERIAL E MÉTODOS}

O solo foi amostrado na Fazenda Bastos Dutra, propriedade privada, com uma área de 1000 ha, localizada no município de Cerejeiras/RO, distante $820 \mathrm{~km}$ da capital Porto Velho, dentro da Chapada dos Parecis, em regiáo de transiçáo de Cerrado para a Floresta Amazônica, numa altitude de 200 a $300 \mathrm{~m}$. O solo é classificado segundo Embrapa (1999) como Latossolo Vermelho-Amarelo distrófico, de textura média.

O clima da regiáo, segundo a classificaçáo de Koppen é Tropical-Quente e Úmido Aw, com estaçáo seca bem definida (junho/setembro), temperatura média de $28^{\circ} \mathrm{C}$, precipitação anual de $2.250 \mathrm{~mm}$ e umidade relativa do ar elevada, oscilando em torno de 85\% (Sedam 2011).

Foram selecionadas cinco áreas sob diferentes sistemas de uso: cultivo de pastagem, sistema de plantio direto, sistema de cultivo mínimo, sistema de plantio convencional e como testemunha a vegetação natural de floresta (Tabela 1 ).

A amostragem do solo, para a determinação da fertilidade e das variáveis, foi realizada em duas profundidades $(0-10 \mathrm{~cm}$ e 10-20 cm), na entrelinha das culturas. Realizou-se uma coleta no mês de abril de 2009 de forma sistemática, em dois alinhamentos principais paralelos entre si ("transectos paralelos"), com cinco retas transversais a eles, e em cada uma destas retas foram coletadas cinco sub-amostras em cada uma das profundidades, formando uma amostra composta de aproximadamente $500 \mathrm{~g}$, por profundidade. Este procedimento foi repetido em todas as retas transversais, totalizando cinco repetiçôes. As amostras foram armazenadas em sacos plásticos e transportadas sob refrigeraçáo até o laboratório de solos da Fundação Universidade Federal de Rondônia, onde foram realizadas as análises. 
Tabela 1 - Histórico do uso do Latossolo Vermelho-Amarelo distrófico nas áreas sob vegetação nativa de floresta (vegetação nativa), cultivo de pastagem (pastagem), sistema de plantio direto (sistema de plantio direto), sistema de cultivo mínimo (sistema de plantio convencional) e sistema de plantio convencional (sistema de plantio convencional), em Cerejeiras/RO.

\begin{tabular}{|c|c|c|}
\hline Tratamento & Área (ha) & Histórico da área \\
\hline vegetação nativa & 300 & $\begin{array}{l}\text { Esta área é de vegetação primária típica de floresta amazônica, classificada como arbórea densa com extrato arbóreo/ } \\
\text { arbustivo de 8-15 metros e densidade de dossel de } 50 \text { a 95\%. }\end{array}$ \\
\hline pastagem & 150 & $\begin{array}{l}\text { A pastagem é exclusivamente de Brachiaria brizantha cv. marandu, foi implantada no ano de } 1999 \text { e não se faz uso de } \\
\text { adubação e calagem. }\end{array}$ \\
\hline $\begin{array}{l}\text { sistema de plantio } \\
\text { direto }\end{array}$ & 200 & $\begin{array}{l}\text { Como as demais áreas, era constituída de vegetação nativa, sendo posteriormente cultivado com pastagem (Brachiaria } \\
\text { brizantha cv. marandu), no ano de } 2005 \text { a pastagem foi dessecada, incorporada ao solo mediante aração e gradagem, } \\
\text { foi realizada calagem para elevar a saturação de bases para } 60 \% \text { e adubação a partir da análise química do solo e } \\
\text { recomendação para a cultura da soja. Em todos os anos seguintes cultivou-se soja durante a safra (outubro-fevereiro) } \\
\text { e manteve-se a vegetação espontânea na entressafra, para o acúmulo de palhada. } 0 \text { calcário utilizado é com PRNT de } \\
100 \% \text { e as fontes de fósforo e potássio são superfosfato simples e cloreto de potássio, respectivamente. }\end{array}$ \\
\hline $\begin{array}{l}\text { sistema de plantio } \\
\text { convencional }\end{array}$ & 200 & $\begin{array}{l}\text { Histórico idêntico ao sistema de plantio direto, sendo que a partir de } 2006 \text { passou a ser realizado o cultivo mínimo, com } \\
\text { a operação de subsolagem de conservação no preparo do solo, em todos os anos a cultura da soja é implantada em } \\
\text { meados de outubro e colhida no início de fevereiro, em seguida cultiva-se o milho safrinha, que é colhido no final de maio, } \\
\text { no mesmo mês é plantado o milheto apenas para cobertura do solo. A adubação é realizada apenas para a cultura da } \\
\text { soja, o milho e milheto utilizam a adubação residual, quando o milho apresenta deficiência de N realiza-se a aplicação de } \\
\text { uréia em cobertura. Este sistema foi adotado para controlar a espécie Spermacoce latifolia, vulgarmente conhecida como } \\
\text { erva quente. }\end{array}$ \\
\hline $\begin{array}{l}\text { sistema de plantio } \\
\text { convencional }\end{array}$ & 150 & $\begin{array}{l}\text { Histórico idêntico ao sistema de plantio direto e sistema de plantio convencional, com a diferença que o preparo con- } \\
\text { vencional do solo, com uma aração e duas gradagens foi mantido. Como no sistema de plantio direto também se faz } 0 \\
\text { cultivo da sucessão soja/pousio. No ano de } 2008 \text { foi realizada em agosto uma escarificação para eliminar o pé-de-grade } \\
\text { (camada compactada abaixo de } 20 \mathrm{~cm} \text { de profundidade). }\end{array}$ \\
\hline
\end{tabular}

O carbono orgânico total do solo foi obtido pelo método de oxidação da matéria orgânica por soluçấo sulfocrômica com calor externo e determinação espectrofotométrica do $\mathrm{Cr}^{3+}$, utilizando o fator de 1,72. Para o nitrogênio total do solo foram realizadas pré-digestôes e destilaçóes, conforme o método Kjeldahl, sendo o destilado titulado com $\mathrm{H}_{2} \mathrm{SO}_{4}$ (Tedesco 1995).

A quantificação do carbono da biomassa microbiana foi realizada pelo método fumigação-extração, proposto por Vance et al. (1987) com adaptaçôes propostas por Silva et al. (2007a). O fator de correçáo utilizado foi de 0,33 , descrito por Sparling e West (1998). O nitrogênio da biomassa microbiana foi determinado na mesma soluçáo utilizada para análise do carbono da biomassa microbiana (Silva et al. 2007b) e o fator de correçáo utilizado foi de 0,54 (Brookes et al. 1985). O N contido nos extratos foi determinado por digestáo e destilação pelo método de Kjeldahl.

$\mathrm{O}$ qMiC e qMiN foi calculado dividindo-se carbono da biomassa microbiana:carbono orgânico total e nitrogênio da biomassa microbiana:nitrogênio total do solo, respectivamente. Os resultados foram expressos em percentagem de $\mathrm{C}$ e $\mathrm{N}$ microbiano em relaçáo ao $\mathrm{C} \mathrm{e} \mathrm{N}$ total do solo. De modo semelhante, a relação $\mathrm{C} / \mathrm{N}$ tot e $\mathrm{C} / \mathrm{N}$ mic foi determinada a partir da divisāo de carbono orgânico total:nitrogênio total do solo e carbono da biomassa microbiana:nitrogênio da biomassa microbiana, respectivamente (Lanarv 1988). A caracterização química e granulométrica do solo foi realizada conforme Tedesco (1995) (Tabela 2).
Tabela 2 - Caracterização química e granulométrica da profundidade de 0-20 cm, de um Latossolo Vermelho-Amarelo distrófico em áreas sob vegetação nativa de floresta (vegetação nativa), cultivo de pastagem (pastagem), sistema de plantio direto (sistema de plantio direto), sistema de cultivo mínimo (sistema de plantio convencional) e sistema de plantio convencional (sistema de plantio convencional), em Cerejeiras/R0.

\begin{tabular}{|c|c|c|c|c|c|}
\hline \multirow{2}{*}{$\begin{array}{c}\text { Atributos de } \\
\text { caracterização' }\end{array}$} & \multicolumn{5}{|c|}{ Cobertura vegetal $^{3}$} \\
\hline & VNF & $\mathrm{CP}$ & SPD & SCM & SPC \\
\hline $\mathrm{pH}_{\text {áqua }}$ & 6,60 & 6,20 & 5,90 & 5,60 & 5,90 \\
\hline$P_{\text {mehlich }}{ }^{-1}$ & 1,84 & 3,48 & 5,13 & 4,87 & 9,07 \\
\hline $\mathrm{K}_{\text {menlich }}{ }^{-1}$ & 0,36 & 0,33 & 0,58 & 0,45 & 0,39 \\
\hline $\mathrm{Ca}+\mathrm{Mg}$ & 3,72 & 1,16 & 3,50 & 3,26 & 3,48 \\
\hline $\mathrm{Al}$ & 0,00 & 0,00 & 0,00 & 0,00 & 0,00 \\
\hline $\mathrm{H}+\mathrm{Al}$ & 2,73 & 2,74 & 2,60 & 2,73 & 2,73 \\
\hline CTC & 6,80 & 4,23 & 6,68 & 6,44 & 6,60 \\
\hline V & 59,87 & 35,17 & 61,60 & 57,59 & 58,63 \\
\hline Areia $^{2}$ & 588,00 & 608,00 & 562,00 & 569,00 & 569,00 \\
\hline Silte $^{2}$ & 92,00 & 67,00 & 98,00 & 84,00 & 71,00 \\
\hline Argila $^{2}$ & 320,00 & 325,00 & 340,00 & 347,00 & 360,00 \\
\hline
\end{tabular}

${ }_{1}^{1} \mathrm{Ph}$ : potencial hidrogeniônico (1:1); p: fósforo $\left(\mathrm{mg} \mathrm{kg}^{-1}\right)$; $\mathrm{k}$ : potássio $(\mathrm{mg} \mathrm{kg}$ 1); ca+mg: cálcio+magnésio (cmolc kg-1); al: alumínio (cmolc kg-1); $\mathrm{h}+\mathrm{al}$ : hidrogênio + alumínio (cmolc $\left.\mathrm{kg}^{-1}\right)$; ctc: capacidade de troca de cátions (cmolc $\left.\mathrm{kg}^{-1}\right)$; $v$ saturação de bases (\%);

${ }^{2}$ fração física do solo expressa em g kg-1.

${ }^{3}$ Vegetação natural de floresta (vegetacão nativa), cultivo de pastagem (pastagem), sistema de plantio direto (sistema de plantio direto), sistema de cultivo mínimo (sistema de plantio convencional) e sistema de plantio co nvencional (sistema de plantio convencional). 
A análise estatística consistiu na análise de dados discrepantes, pelo método de Chauvenet, e dos pressupostos das variâncias, pelo teste de Bartlett e de Shapiro-Wilk, seguidos do teste de Kruskal-Wallis, entre os tratamentos, e comparação das variáveis entre as profundidades, pelo teste de Mann-Whitney, todos ao nível de 5\% de probabilidade. Para a avaliação conjunta de todas as variáveis foi empregada a análise de agrupamentos pelo método de Ward (Khatree e Naik 2000).

\section{RESULTADOS E DISCUSSÃO}

O carbono orgânico e o nitrogênio total do solo diferiram significativamente entre os tratamentos (Tabela 3) e entre as profundidades (Tabela 4), com exceçáo do sistema de plantio convencional, que apresentou homogeneidade entre as camadas de 0-10 e 10-20 cm. Na profundidade de 0-10 cm, observa-se que o solo sob vegetaçáo nativa demonstrou maior valor de carbono orgânico total, seguido do solo sob pastagem, plantio convencional, plantio direto e cultivo mínimo, sendo que estes dois últimos não apresentaram diferença significativa (Tabela 3). O nitrogênio total foi maior no solo sob vegetaçáo nativa, seguido de pastagem, sistema de plantio direto, de plantio convencional e do cultivo mínimo (Tabela 3). Júnior e Melo (2000), também verificaram valores significativamente maiores de carbono orgânico total no tratamento com vegetação natural e menores nos tratamentos onde houve preparo do solo, na camada superficial do solo. Os maiores níveis destas variáveis em vegetação nativa são explicados pela sua maior diversidade de espécies e a decomposição diferenciada dos resíduos vegetais, que retornam ao solo de forma mais contínua (Alvarenga et al. 1999).
Com relação ao carbono orgânico total, a ausência de diferença significativa entre vegetação nativa e pastagem é explicada pelo aporte contínuo de biomassa das espécies do gênero Brachiaria, devido à constante renovaçăo do sistema radicular (Luizão et al. 1999; Cenciani 2007).

Wendling et al. (2005), avaliando o carbono orgânico total num Latossolo Vermelho sob diferentes manejos, com um tempo de cultivo de quatro anos, encontraram uma diminuição significativa nos teores de carbono orgânico total no sistema de preparo convencional em comparaçáo a preparos conservacionistas, o que náo se repetiu neste trabalho, pois no sistema de plantio convencional obteve-se maior teor desta variável do que no sistema de plantio direto e cultivo mínimo, na camada superficial, e maior até que a vegetação nativa e pastagem, na camada subsuperficial (Tabela 3). Comportamento semelhante ocorreu no nitrogênio total do solo, onde o sistema de plantio convencional foi superior ao sistema de plantio convencional na profundidade de 0-10 $\mathrm{cm}$, e na profundidade de $10-20 \mathrm{~cm}$ não diferiu do sistema de plantio direto e foi superior a pastagem e ao sistema de cultivo mínimo (Tabela 3).

Estes resultados podem ser explicados pelo fato do sistema de plantio convencional analisado acumular massa vegetal durante o período de pousio, que é incorporada no preparo do solo, não deixando o solo descoberto por longos períodos e também pelo fato do tempo de cultivo ser de cinco anos, e como afirma Souza (2005), as respostas do carbono orgânico total e nitrogênio total do solo às mudanças promovidas pelo manejo do solo podem ser imperceptíveis durante até dez anos.

Tabela 3 - Média do carbono orgânico total (COT), carbono da biomassa microbiana do solo (CBM), quociente microbiano do carbono (qMiC), nitrogênio total do solo (NTS), nitrogênio da biomassa microbiana (NBM), quociente microbiano do nitrogênio (qMiN), relação entre 0 carbono e o nitrogênio total do solo (C/N tot) e relação entre o carbono e o nitrogênio da biomassa microbiana do solo (C/N mic), em duas profundidades $(0-10$ e 10-20 cm), em amostras de solo sob vegetação natural de floresta (VNF), cultivo de pastagem (CP), sistema de plantio direto (SPD), sistema de cultivo mínimo (SCM) e sistema de plantio convencional (SPC) em Cerejeiras/RO.

\begin{tabular}{|c|c|c|c|c|c|c|c|c|c|}
\hline $\begin{array}{l}\text { Profundidade } \\
\qquad(\mathrm{cm})\end{array}$ & Tratamento & $\begin{array}{c}\text { COT } \\
\left(\mathrm{g} \mathrm{kg}^{-1}\right)\end{array}$ & $\begin{array}{c}\mathrm{CBM} \\
\left(\mathrm{mg} \mathrm{kg}^{-1}\right)\end{array}$ & $\begin{array}{l}\text { qMiC } \\
(\%)\end{array}$ & $\begin{array}{c}\text { NTS } \\
\left(\mathrm{g} \mathrm{kg}^{-1}\right)\end{array}$ & $\begin{array}{c}\mathrm{NBM} \\
\left(\mathrm{mg} \mathrm{kg}^{-1}\right)\end{array}$ & $\begin{array}{l}\text { qMiN } \\
(\%)\end{array}$ & $\mathrm{C} / \mathrm{N}$ tot & $\mathrm{C} / \mathrm{N}$ mic \\
\hline \multirow{5}{*}{$0-10$} & VNF & $17,33 \mathrm{a}$ & $503,43 a$ & $3,03 \mathrm{a}$ & $1,41 \mathrm{a}$ & $39,03 \mathrm{a}$ & $2,80 \mathrm{a}$ & $12,25 \mathrm{a}$ & $12,92 \mathrm{a}$ \\
\hline & $\mathrm{CP}$ & $14,73 \mathrm{~b}$ & $387,15 \mathrm{a}$ & $2,64 \mathrm{a}$ & $1,21 \mathrm{~b}$ & $18,34 \mathrm{~b}$ & $1,55 \mathrm{~b}$ & $12,31 \mathrm{a}$ & $22,05 \mathrm{a}$ \\
\hline & SPD & $12,72 d$ & 290,11 b & $2,30 \mathrm{~b}$ & $1,15 \mathrm{c}$ & $22,39 \mathrm{c}$ & $2,08 \mathrm{C}$ & $11,28 \mathrm{a}$ & $17,78 \mathrm{a}$ \\
\hline & SCM & $12,69 d$ & $261,20 \mathrm{C}$ & $2,08 \mathrm{c}$ & $0,97 \mathrm{e}$ & $14,18 d$ & $1,48 \mathrm{bc}$ & $13,22 \mathrm{a}$ & $19,56 \mathrm{a}$ \\
\hline & SPC & $13,15 \mathrm{c}$ & $184,22 d$ & $1,41 d$ & $1,05 d$ & $12,63 \mathrm{e}$ & $1,22 d$ & $12,66 \mathrm{a}$ & $15,36 \mathrm{a}$ \\
\hline \multirow{5}{*}{$10-20$} & VNF & $9,35 \mathrm{~b}$ & $273,37 \mathrm{~b}$ & $3,07 \mathrm{~b}$ & $1,09 \mathrm{a}$ & $27,22 \mathrm{a}$ & $2,49 a$ & $10,27 \mathrm{a}$ & $8,74 \mathrm{e}$ \\
\hline & $\mathrm{CP}$ & $9,61 \mathrm{~b}$ & $310,57 \mathrm{a}$ & $3,24 \mathrm{a}$ & $0,85 \mathrm{c}$ & $15,20 \mathrm{~b}$ & $1,78 \mathrm{a}$ & $26,46 \mathrm{a}$ & $11,45 b$ \\
\hline & SPD & $9,17 \mathrm{~b}$ & 204,64 c & $2,25 c$ & $0,93 \mathrm{~b}$ & $10,57 \mathrm{c}$ & $1,25 a$ & $60,11 \mathrm{a}$ & $9,96 \mathrm{~d}$ \\
\hline & SCM & $8,62 \mathrm{c}$ & $150,97 d$ & $1,79 \mathrm{~d}$ & $0,81 d$ & $8,53 \mathrm{c}$ & $1,07 \mathrm{a}$ & $19,00 \mathrm{a}$ & $10,75 \mathrm{c}$ \\
\hline & SPC & $13,43 a$ & $129,39 d$ & $1,00 \mathrm{e}$ & $0,95 b$ & $12,73 \mathrm{~b}$ & $1,39 a$ & $11,43 a$ & $14,54 \mathrm{a}$ \\
\hline
\end{tabular}

Letras iguais na mesma coluna e profundidade indicam que não há diferença significativa entre as médias pelo teste de Kruskal-Wallis, ao nível de $5 \%$ de probabilidade. 
A homogeneidade dos teores de carbono orgânico total na profundidade de $10-20 \mathrm{~cm}$ entre os tratamentos vegetaçáo nativa, pastagem e sistema de plantio direto também foi verificada por Carvalho (2006), que estudou a conversão da vegetaçâo natural para fins agrícolas na Amazônia e afirmou que a mudança de uso da terra influenciou o carbono orgânico total do solo somente até $10 \mathrm{~cm}$ de profundidade.

Com relação às profundidades dentro de cada tratamento, somente o sistema de plantio convencional não apresentou diferença significativa para o carbono orgânico e nitrogênio total do solo entre as profundidades analisadas (Tabela 4), o que se deve a homogeneização das camadas com o revolvimento do solo. Nos tratamentos vegetação nativa, pastagem, sistema de plantio direto e sistema de cultivo mínimo, os maiores níveis foram constatados na profundidade de $0-10 \mathrm{~cm}$, o que corrobora com a afirmaçáo de Hernani et al. (1999), de que o não revolvimento do solo contribui para a concentraçáo de carbono orgânico total em sua camada superficial. Quanto ao nitrogênio total do solo, sistema de plantio convencional e cultivo mínimo não apresentaram diferença significativa entre as profundidades, o que também se deve ao revolvimento do solo, nos demais tratamentos foi constatada a mesma resposta observada para carbono orgânico total do solo.

A ordem do carbono orgânico e nitrogênio total do solo apresentou-se diferente, pois o sistema de plantio convencional supera o sistema de plantio direto, quanto ao teor de carbono orgânico, o que não ocorre quanto ao nitrogênio total do solo (Tabela 3), refletindo numa maior manutenção de $\mathrm{N}$ no sistema onde não há o revolvimento do solo, tendo em vista

Tabela 4 - Valores de probabilidade utilizando o teste de Mann-Whitney Cerejeiras/RO

\begin{tabular}{cccccc}
\hline \multirow{2}{*}{ Variáveis $^{1}$} & \multicolumn{5}{c}{ Cobertura vegetal $^{2}$} \\
\cline { 2 - 6 } & VNF & CP & SPD & SCM & SPC \\
\hline COT & $0,0079^{3}$ & 0,0119 & 0,0112 & 0,0079 & 0,7533 \\
CBM & 0,0952 & 0,0952 & 0,4206 & 0,0159 & 0,3096 \\
qMiC & 0,9999 & 0,0556 & 0,9999 & 0,8413 & 0,3036 \\
NTS & 0,0114 & 0,0099 & 0,0159 & 0,070 & 0,3290 \\
NBM & 0,0080 & 0,5476 & 0,2222 & 0,0361 & 0,9999 \\
qMiN & 0,5476 & 0,6905 & 0,2222 & 0,0925 & 0,4206 \\
C/N tot & 0,0556 & 0,4206 & 0,1518 & 0,0317 & 0,3095 \\
C/N mic & 0,0952 & 0,9999 & 0,3095 & 0,8413 & 0,3095 \\
\hline
\end{tabular}

${ }^{1}$ Carbono orgânico total (COT), carbono da biomassa microbiana do solo (CBM), quociente microbiano do carbono (qMiC), nitrogênio total do solo (NTS), nitrogênio da biomassa microbiana (NBM), quociente microbiano do nitrogênio (qMiN), relação entre 0 carbono e o nitrogênio total do solo (C/N tot) e da relação entre 0 carbono e 0 nitrogênio da biomassa microbiana do solo (C/N mic) ${ }^{2}$ Vegetacão natural de floresta (VNF), cultivo de pastagem (CP) sistema de plantio direto (SPD), sistema de cultivo mínimo (SCM) e sistema de plantio convencional (SPC). ${ }^{3}$ Valores inferiores a 0,05 diferem significativamente entre as profundidades de 0-10 e 10-20 cm. que os dois tratamentos possuem o mesmo histórico e são cultivados com a mesma sucessão (soja/pousio).

$\mathrm{Na}$ variável relação $\mathrm{C} / \mathrm{N}$ tot não se observa diferença significativa entre os tratamentos nas duas profundidades $(0-10$ e $10-20 \mathrm{~cm})$ (Tabela 3), demonstrando um possível equilíbrio na mineralização do $\mathrm{N}$ em todos os usos do solo nas duas profundidades. Somente no sistema de cultivo mínimo constatou-se diferença significativa entre as profundidades (Tabela 4), obtendo maior teor na profundidade de $10-20 \mathrm{~cm}$.

O comportamento pouco esclarecedor das variáveis químicas com relaçấo aos sistemas de cultivo é explicado pela afirmação de Carvalho (2006), de que as pesquisas não são conclusivas com relação ao acúmulo ou manutenção de matéria orgânica em sistema de plantio direto, pois enquanto resultados apontam um incremento em seus teores (Oliveira et al. 2004), outros não apresentam diferenças significativas tanto para tratamentos com vegetaçáo natural, quanto para sistema de plantio convencional (Freitas et al. 2000; Roscoe e Buurman 2003).

As variáveis microbiológicas foram mais sensíveis às alteraçōes no uso do solo, sendo que os teores de carbono e nitrogênio da biomassa microbiana aumentaram de acordo com a reduçáo de revolvimento do solo, concordando com a afirmação de Gama-Rodrigues et al. (2005), de que analisando a biomassa microbiana obtém-se respostas mais rápidas às modificaçóes no uso do solo do que a matéria orgânica. Na profundidade de $0-10 \mathrm{~cm}$, solo sob vegetaçáo nativa apresentou teor significativamente maior de carbono da biomassa microbiana, seguido da pastagem, sistema de plantio direto, sistema de cultivo mínimo e sistema de plantio convencional. $\mathrm{Na}$ profundidade de $10-20 \mathrm{~cm}$, pastagem foi o tratamento de maior teor significativo de carbono da biomassa microbiana, seguido da vegetação nativa, sistema de plantio direto, sistema de cultivo mínimo e sistema de plantio convencional (Tabela 3). No solo sob vegetaçâo nativa obteve-se maior teor de nitrogênio da biomassa microbiana, seguido do solo sob pastagem, plantio direto, cultivo mínimo e plantio convencional, na profundidade de $0-10 \mathrm{~cm}$, o mesmo ocorre na profundidade de $10-20 \mathrm{~cm}$, com exceção do sistema de plantio direto e o do sistema de plantio convencional, nos quais não foi constatada diferença significativa (Tabela 3).

O valor mais elevado de carbono e nitrogênio da biomassa microbiana no solo sob vegetação nativa se deve ao aporte contínuo e diversificado de matéria orgânica incorporada ao solo, principalmente via deposição pelas plantas, pois segundo Matsuoka et al. (2003) a diversidade florística das áreas nativas e a presença da vegetaçáo durante todo o ano influenciam a quantidade e a qualidade da serapilheira, fato este que pode ter implicado num maior acúmulo de $\mathrm{C}$ e $\mathrm{N}$ pela biomassa microbiana, consequentemente, melhores condiçóes de desenvolvimento da microbiota. 
O teor de carbono da biomassa microbiana no solo sob pastagem não diferiu estatisticamente, na camada de $0-10 \mathrm{~cm}$, do solo sob vegetaçáo nativa, e foi significativamente maior que os demais tratamentos na profundidade de $10-20 \mathrm{~cm}$. Constatou-se também diferença significativa para nitrogênio da biomassa microbiana, sendo o teor de carbono do solo sob pastagem superior ao do plantio direto, do cultivo mínimo e do plantio convencional, nas duas profundidades. Estes resultados sáo explicados por Santos et al. (2007) que afirmam que as pastagens perenes, sobretudo aquelas constituídas por gramíneas, possuem um grande efeito rizosférico sobre os microrganismos, por seu sistema radicular ser muito denso e apresentar renovação intensa. Neste contexto, Cenciani (2007) também afirma que espécies do gênero Brachiaria possuem elevada capacidade de armazenar $\mathrm{C}$ no solo, devido à sua grande produção de massa seca e, principalmente à intensa renovação do seu sistema radicular abundante e permanente, fato este constatado também por Araújo et al. (2011).

Segundo Perez et al. (2004), nas condiçóes de mata nativa, a deposição contínua de resíduos orgânicos, a grande quantidade de raízes e a maior quantidade de água retida no solo estimulam a manutençấo da biomassa microbiana, enquanto solos submetidos à atividade agrícola, devido à perturbação imposta, normalmente apresentam decréscimo da mesma. Em solos sob vegetaçáo nativa os maiores teores de carbono e nitrogênio da biomassa microbiana podem ser atribuídos ao acúmulo de serapilheira, que condiciona menor variaçáo e níveis mais adequados de temperatura e umidade (Matsuoka et al. 2003). Com isso sistemas de cultivo que proporcionem condiçôes semelhantes à vegetaçáo natural podem manter níveis mais elevados de carbono da biomassa microbiana e nitrogênio da biomassa microbiana. Considerando estes aspectos, a ausência de revolvimento, pode ser uma estratégia importante, pois proporciona um arranjo natural das partículas minerais, que permite maior retenção de água do que sistemas que revolvem o solo periodicamente. Estas afirmações explicam o fato de que no plantio direto, apesar de se constatar níveis de carbono e nitrogênio da biomassa microbiana inferiores aos da vegetaçáo nativa e da pastagem, nas duas profundidades, observa-se maior teor do que no cultivo mínimo e no plantio convencional (Tabela 3), que possuem a prática de revolvimento do solo.

$\mathrm{O}$ teor de nitrogênio da biomassa microbiana maior no sistema de plantio direto do que no sistema de plantio convencional sugere uma melhor condiçâo para a biomassa microbiana do solo e menor perda do $\mathrm{N}$ para o sistema. Amado et al. (1999) relatam que o uso de leguminosas associado ao plantio direto é uma eficiente estratégia para conservar o $\mathrm{N}$ no solo. No solo sob sistema de cultivo mínimo foi constatado menor teor de nitrogênio total do solo do que no solo plantio convencional, na profundidade de $0-10 \mathrm{~cm}$, e situação inversa com relação ao nitrogênio da biomassa microbiana, de forma semelhante ao carbono orgânico total e carbono da biomassa microbiana, confirmando que a diminuição do revolvimento do solo favorece a microbiota.

Nos tratamentos vegetaçáo nativa e sistema de cultivo mínimo obteve-se diferença significativa entre as duas profundidades para o nitrogênio da biomassa microbiana (Tabela 4), concentrando valores maiores na camada superficial do solo $(0-10 \mathrm{~cm})$ (Tabela 3).

Diversos estudos relacionados ao estudo do carbono da biomassa microbiana em floresta nativa, sistema de plantio direto, sistema de plantio convencional em Latossolos indicam que os teores carbono da biomassa microbiana mantiveramse significativamente maiores na camada de $0-10 \mathrm{~cm}$ de profundidade, independentemente das características das áreas estudadas (Perez et al. 2004; Conceiçâo et al. 2005; Ferreira et al. 2007).

Apesar de os maiores valores de carbono da biomassa microbiana concentrarem-se na profundidade de $0-10 \mathrm{~cm}$, não houve diferença significativa entre as profundidades, dentro de cada tratamento (Tabela 4), fato também observado por Silva et al. (2010), analisando o carbono da biomassa microbiana de um Latossolo Vermelho-Amarelo sob Cerrado nativo, sistema de plantio direto e de cultivo convencional. O que pode ser explicado pela diversidade florística e pela profundidade do sistema radicular em vegetaçáo nativa; o efeito rizosférico em pastagem e a presença de leguminosas nos três diferentes sistemas de preparo do solo podem explicar a ausência de diferença significativa entre as profundidades.

O comportamento do $\mathrm{qMiC}$ foi semelhante ao do carbono da biomassa microbiana, os tratamentos diferiram estatisticamente, sendo que os de maior teor foram vegetação nativa e pastagem, seguidos do sistema de plantio direto, sistema de cultivo mínimo e sistema de plantio convencional (Tabela 3). O qMiC expressa quanto do carbono orgânico total está imobilizado na biomassa microbiana do solo, com isso observa-se que a maior eficiência dos microrganismos em imobilizar o $\mathrm{C}$ apresentou tendência inversamente proporcional à menor intensidade de manejo do solo. Wardle (1994) afirma que baixos valores de qMiC podem ocorrer pela microbiota estar sob algum fator de estresse, ou, como propóem Gama-Rodrigues et al. (2008) devido à baixa qualidade nutricional da matéria orgânica, fazendo com que a biomassa microbiana torne-se incapaz de utilizar totalmente o carbono orgânico total.

Nesta ótica os valores significativamente menores de qMiC principalmente no sistema de cultivo mínimo e plantio convencional sugerem uma provável condição de estresse para biomassa microbiana, possivelmente ocasionada pelo revolvimento intenso do solo no cultivo mínimo, e uma baixa qualidade do substrato orgânico no sistema de plantio 
convencional, que possui duas gramíneas (milho/milheto) em sucessáo com alta relação C/N (Silva et al. 2009; Calvo et al. 2010).

Teores mais elevados de carbono da biomassa microbiana e nitrogênio da biomassa microbiana implicam maior imobilização temporária de nutrientes e, consequentemente, menores perdas de nutrientes no sistema solo-planta (Mercante et al. 2004) e aliados ao qMiC que é considerado medida da qualidade nutricional da matéria orgânica (Wardle 1994) trazem informaçóes importantes acerca da qualidade do solo. Baseando-se nessas evidências, pode-se afirmar que a exploração agrícola sob qualquer sistema de cultivo afetou a qualidade do solo e que, dentre os sistemas de manejo, o sistema de plantio direto apresentou melhor qualidade nutricional da matéria orgânica e maior acúmulo de carbono da biomassa microbiana que os demais.

Analisando o qMiN, na profundidade de $0-10 \mathrm{~cm}$, que apresentou diferença estatística entre os tratamentos, sendo maior no solo sob vegetaçáo nativa, seguido por pastagem, cultivo mínimo, plantio direto e plantio convencional (Tabela 3), observa-se que onde náo há revolvimento do solo, ou pelo menos onde esse revolvimento é reduzido, a biomassa microbiana teve maior eficiência de utilizar o N. Um fato interessante é que a biomassa microbiana do sistema de plantio convencional foi mais eficiente em utilizar o $\mathrm{N}$ até mesmo em sistemas onde houve maior teor de nitrogênio total do solo (sistema de plantio convencional) e igualou-se a cultivos mais conservacionistas, como o sistema de plantio direto, e com maior efeito rizosférico sobre microorganismos, como o pastagem, esta evidência pode ser explicada pela alta relaçáo $\mathrm{C} / \mathrm{N}$ da palhada das duas gramíneas da sucessão soja/milho/milheto (Silva et al. 2009; Calvo et al. 2010), que proporciona uma imobilizaçáo do $\mathrm{N}$ mineral por parte da biomassa microbiana (Perin et al. 2004). Já o qMiN na profundidade de $10-20 \mathrm{~cm}$ náo obteve diferença significativa entre os tratamentos (Tabela 3), mostrando que a microbiota apresentou a mesma eficiência em imobilizar o $\mathrm{N}$ em todos os tratamentos nessa profundidade.

O quociente metabólico é considerado um índice para avaliar o efeito das condiçóes de estresse sobre a atividade da biomassa microbiana do solo (Anderson e Domsch 1993), a relaçáo $\mathrm{C} / \mathrm{N}$ mic, o qMiC e o qMiN expressam a eficiência da microbiota do solo em imobilizar $\mathrm{C}$ e $\mathrm{N}$ em funçáo da qualidade nutricional da matéria orgânica (Sparling 1992). Gama-Rodrigues et al. (2008) afirmam que a relação $\mathrm{C} / \mathrm{N}$ mic indica o potencial de mineralização de $\mathrm{N}$ e mudanças na composição microbiana, Li et al. (2004) relatam que valores acima de 10 indicariam predomínio de fungos e, abaixo deste valor, predomínio de bactérias.

Considerando as afirmaçóes acima e avaliando os resultados da relação $\mathrm{C} / \mathrm{N}$ mic, na profundidade de $0-10 \mathrm{~cm}$ (Tabela 3), observa-se que todos os tratamentos apresentam o mesmo potencial de mineralização de $\mathrm{N}$ e apresentam evidências de possuírem predomínio de fungos na biomassa microbiana no solo. Na profundidade de $10-20 \mathrm{~cm}$, constata-se que sistema de plantio convencional possui maior capacidade de mineralização de $\mathrm{N}$, seguido pela pastagem, sistema de cultivo mínimo, sistema de plantio direto e vegetação nativa, observase ainda que no solo sob vegetação nativa e sistema de plantio direto predominam bactérias na biomassa microbiana do solo.

Na Figura 1 pode-se observar o agrupamento dos tratamentos estudados para a avaliação dos atributos químicos e biológicos. Com esta análise pode-se dividir os tratamentos em dois grupos ( 1 e 2), aqueles que se encontram no mesmo grupo são considerados semelhantes para todas as variáveis avaliadas pela análise de agrupamentos, com isso os três sistemas de preparo (plantio direto, cultivo mínimo e plantio convencional) que compóem o grupo 1 apresentaram semelhança entre si, considerando as variáveis analisadas (carbono orgânico total, carbono da biomassa microbiana, nitrogênio total do solo, nitrogênio da biomassa microbiana, qMiC, qMiN, relação $\mathrm{C} / \mathrm{N}$ to e relação $\mathrm{C} / \mathrm{N}$ mic), sendo que no sistema de plantio direto e no sistema de plantio convencional observou-se semelhança ainda maior, e os demais tratamentos (vegetação nativa e pastagem) formaram o grupo 2. Observa-se desta forma que os diferentes sistemas assemelham-se entre si e diferem do estado natural e da pastagem.

Quando se realiza a análise de agrupamentos entre os tratamentos e profundidades avaliados, obtem-se três grupos distintos (Figura 2), onde sistema de cultivo mínimo e sistema de plantio direto na profundidade de $0-10 \mathrm{~cm}$; vegetação nativa e pastagem na profundidade de $10-20 \mathrm{~cm}$ constituem o grupo 1, enquanto sistema de cultivo mínimo e sistema de plantio direto de $10-20 \mathrm{~cm}$, e sistema de plantio convencional

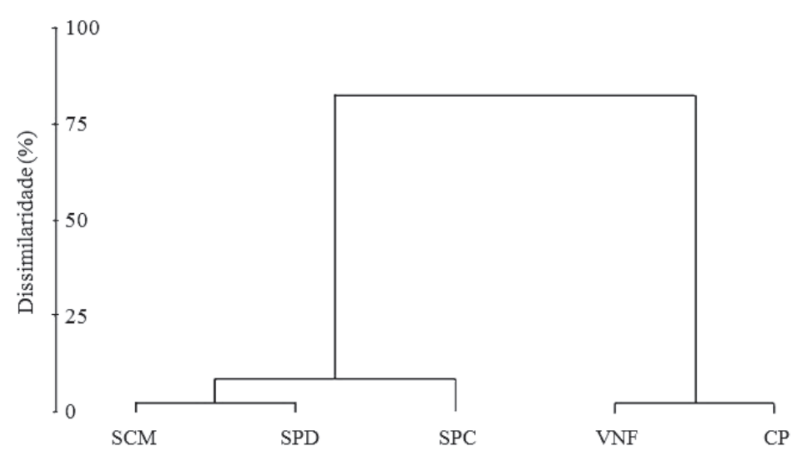

Figura 1 - Análise de agrupamento utilizando o método de Ward, para as variáveis químicas e biológicas em solo sob vegetação natural de floresta (VNF), cultivo de pastagem (CP), sistema de plantio direto (SPD), sistema de cultivo mínimo (SCM) e sistema de plantio convencional (SPC) em Cerejeiras/R0. 


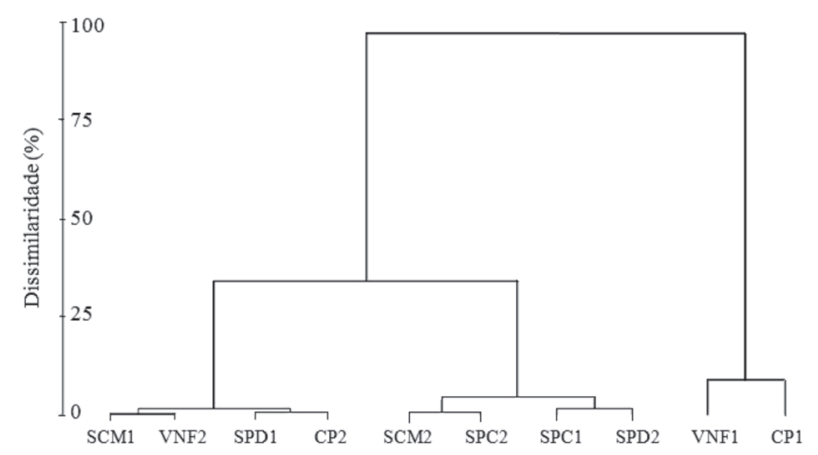

Figura 2 - Análise de agrupamento utilizando 0 método de Ward, para as variáveis químicas e biológicas em solo sob vegetação natural de floresta (VNF), cultivo de pastagem (CP), sistema de plantio direto (SPD), sistema de cultivo mínimo (SCM) e sistema de plantio convencional (SPC) em Cerejeiras/ RO. Tratamentos seguidos de 1 e 2 representam a profundidade de $0-10 \mathrm{~cm}$ e 10-20 cm, respectivamente.

de 0-10 e 10-20 cm formam o grupo 2; e por fim, vegetação nativa e pastagem $0-10 \mathrm{~cm}$ representam o grupo 3 .

Avaliando a distribuição destes grupos percebe-se que os tratamentos com menores teores das variáveis estudadas podem ser agrupados com os tratamentos de comportamento inverso, contudo a semelhança entre estes reside na profundidade de $0-10 \mathrm{~cm}$ dos tratamentos onde se obtiveram menores valores na maioria das variáveis (plantio convencional, cultivo mínimo e de plantio direto) com a profundidade de 10-20 $\mathrm{cm}$ dos tratamentos com valores maiores (vegetaçáo nativa e pastagem). Vegetação nativa e pastagem possuem semelhança também considerando as profundidades, pois, vegetação nativa e cultivo de pastagem, na camada de $0-10 \mathrm{~cm}$, constituem um mesmo grupo (Grupo 3) e vegetação nativa e cultivo de pastagem, na profundidade de $10-20 \mathrm{~cm}$, encontram-se também num mesmo grupo (Grupo 1).

A camada superficial $(0-10 \mathrm{~cm})$ dos tratamentos sistema de cultivo mínimo e sistema de plantio direto assemelha-se à profundidade de $10-20 \mathrm{~cm}$ da vegetação nativa (testemunha deste trabalho) e do cultivo de pastagem, deste modo a análise de agrupamentos vem ratificar a análise estatística, ou seja, a diminuição e a ausência das operaçôes de preparo do solo são importantes estratégias para conservar e aumentar os níveis dos indicadores de qualidade de solo avaliados.

Com base nos resultados discutidos nota-se que o cultivo mais recomendado, visando à conservação do solo, seria o de pastagem, e para a prática de agricultura seria o plantio direto. Contudo os atributos avaliados não são suficientes para determinar a qualidade do solo, sendo recomendável, avaliar também a parte física, a partir de atributos como a densidade aparente e de partículas do solo, a taxa de infiltraçáo, porosidade, entre outros, para que deste modo, realize-se uma caracterização completa do solo, e estudos deste cunho, em diferentes épocas do ano e em cronossequência.

\section{CONCLUSÕES}

Os diferentes usos do solo influenciam as variáveis avaliadas, com exceção da relação carbono/nitrogênio total do solo. As variáveis microbiológicas do solo foram mais sensíveis às mudanças do uso e manejo do solo. O sistema de plantio convencional é o tratamento que apresenta maior homogeneidade entre as profundidades. $\mathrm{O}$ solo sob vegetaçáo nativa, cultivo de pastagem, sistema de plantio direto e sistema de cultivo mínimo demonstra evidências de maior qualidade na profundidade de $0-10 \mathrm{~cm}$. Com a análise de agrupamentos evidencia-se que o solo sob os três sistemas de preparo analisados apresentam semelhanças entre si, assim como, o solo sob vegetação nativa e sob pastagem também se assemelham.

\section{BIBLIOGRAFIA CITADA}

Alvarenga, M.I.N.; Siqueira, J.O.; Davide, A.C. 1999. Teor de carbono, biomassa microbiana, agregação e micorriza em solos de cerrado com diferentes usos. Ciência Agrotécnica, 23: 617-625.

Amado, T.J.C.; Mielniczuk, J. 1999. Plantio direto e rotação de culturas com leguminosas: Uma excelente combinação para promover o incremento da capacidade produtiva do solo. Revista Plantio Direto, 50: 23-27.

Anderson, T.H.; Domsch, K.H. 1989. Rations of microbial biomass carbon to total organic in arable soils. Soil Biology \& Biochemistry, 21: 474-479.

Anderson, T.H.; Domsch, K.H. 1993. The metabolic quocient for $\mathrm{CO} 2$ (qCO2) as a specific activity parameter to assess the effects of environmental conditions, such as $\mathrm{pH}$, on the microbial biomass of forest soils. Soil Biology \& Biochemistry, 25: 393-395.

Araújo, E.A.; Ker, J.C.; Mendonça, E.S.; Silva, I.R; Oliveira, E.K. 2011. Impacto da conversão floresta - pastagem nos estoques e na dinâmica do carbono e substâncias húmicas do solo no bioma Amazônico. Acta Amazonica, 41: 103-114.

Barreto, P.A.B.; Gama-Rodrigues, E.F. da; Gama-Rodrigues, A.C. da; Barros, N.F. de; Fonseca, S. 2008. Atividade microbiana, carbono e nitrogênio da biomassa microbiana em plantaçốes de eucalipto, em seqüência de idades. Revista Brasileira de Ciência do Solo, 32: 611-619.

Brookes, P.C.; Landman, A.; Pruden, G.; Jenkinson, D.S. 1985. Chloroform fumigation and the release of soil nitrogen: a rapid direct extraction method to measure microbial biomass nitrogen in soil. Soil Biology \& Biochemestry, 17: 837-842.

Calvo, L.C; Foloni, J.S.S.; Brancalião, S.R. 2010. Produtividade de fitomassa e relaçáo c/n de monocultivos e consórcios de guanduanão, milheto e sorgo em três épocas de corte. Bragantia, 69: 77-86.

Carvalho, J.L.N. 2006. Conversão do Cerrado para fins agricolas na Amazônia e seus impactos no solo e no ambiente. Dissertação de Mestrado, Escola Superior de Agricultura "Luiz de Queiroz", Universidade de São Paulo, Piracicaba, São Paulo. 95 pp.

Cenciani, K. 2007. Diversidade bacteriana em solos da Amazônia: variabilidade dos gêneros associados ao processo de nitrificaçâo. Tese 
de Doutorado, Escola Superior de Agricultura "Luiz de Queiroz", Universidade de São Paulo, Piracicaba, São Paulo. 103 pp.

Conceição, P.C.; Amado, T.J.C.; Mielniczuk, J.; Spagnollo, E. 2005. Qualidade do solo em sistemas de manejo avaliada pela dinâmica da matéria orgânica e atributos relacionados. Revista Brasileira de Ciência do Solo, 29: 777-788.

Doran, J.W.; Zeiss, M.R. 2000. Soil health and sustainability: managing the biotic component of soil quality. Applied Soil Ecology, 15: 3-11.

Embrapa. 1999. Sistema Brasileiro de Classificação de Solos. Brasília, DF. 412 pp.

Ferreira, E.A.B.; Resck, D.V.S.; Gomes, A.C.; Ramos, M.L.G. 2007. Dinâmica do carbono da biomassa microbiana em cinco diferentes épocas do ano em diferentes sistemas de manejo do solo no cerrado. Revista Brasileira de Ciência do Solo, 31: 1625-1635.

Ferreira, G.M. 2008. Atividade microbiana e agregação de um Latossolo Vermelho Distroférrico em Campinas, SP, sob usos e manejos distintos. Dissertação de Mestrado, Instituto Agronômico de Campinas, Campinas, São Paulo. 70 pp.

Freitas, P.L.; Blancaneaux, P.; Larre-Larrouy, M.C.; Feller, C. 2000. Nível e natureza do estoque orgânico de Latossolos sob diferentes sistemas de uso e manejo. Pesquisa Agropecuária Brasileira, 35: 157-170.

Gama-Rodrigues, E.F.; Gama-Rodrigues, A.C.; Paulino, G.M; Franco, A.A. 2008. Atributos químicos e microbianos de solos sob diferentes coberturas vegetais no norte do estado do rio de janeiro. Revista Brasileira de Ciência do Solo, 32: 1521-1530.

Gama-Rodrigues, E.F.; Barros, N.F.; Gama-Rodrigues, A.C.; Santos, G.A. 2005. Nitrogênio, carbono e atividade da biomassa microbiana do solo em plantaçóes de eucalipto. Revista Brasileira de Ciência do Solo, 29: 893-901.

Hernani, L.C.; Kurihara, C.H.; Silva, W.M. 1999. Sistemas de manejo de solo e perdas de nutrientes e matéria orgânica por erosão. Revista Brasileira de Ciência do Solo, 23: 145-154.

Júnior, M.M.; Melo, W.J. 2000. Alteraçôes na matéria orgânica e na biomassa microbiana em solo de mata natural submetido a diferentes manejos. Pesquisa Agropecuária Brasileira, 35: $1177-$ 1182.

Khatree, R.; Naik, D.N. 2000. Multivariate data reduction and discrimination with $S A S^{\oplus}$ software. Cary: Sas Institute Inc. 558 pp.

Lanarv. Laboratório Nacional de Referência Vegetal. Análise de corretivos, fertilizantes e inoculantes - métodos oficiais. 1988. Brasília, Secretaria Nacional de Defesa Agropecuária - Ministério de Agricultura. 104 pp.

Li, Q.; Allen, H.L. Wollum II, A.G. 2004. Microbial biomass and bacterial functional diversity in forest soils: Effects of organic matter removal, compaction, and vegetation control. Soil Biology \& Biochemistry, 36: 571-579.

Luizão, R.C.C.; Costa, E. S.; Luizão, F.J. 1999. Mudanças na biomassa microbiana e nas transformaçóes de nitrogênio do solo em uma seqüência de idades de pastagens após derruba e queima de floresta na Amazônia Central. Acta Amazonica, 29: 43-56.
Maluche, C. R. D. 2004. Atributos microbiológicos e químicos do solo em sistema de produçâo de maçã convencional e orgânico. Dissertação de Mestrado, Curso de Pós-graduação em Ciência do Solo, Universidade do Estado de Santa Catarina, Lages, Santa Catarina. 72 pp.

Matsuoka, M.; Mendes, I.C.; Loureiro, M.F. 2003. Biomassa microbiana e atividade enzimática em solos sob vegetação nativa e sistemas agrícolas anuais e perenes na região de Primavera do Leste (MT). Revista Brasileira de Ciência do Solo, 27: 425-433.

Mercante, F.M. 2004. Parâmetros microbiológicos como indicadores de qualidade do solo sob sistemas integrados de produção agropecuária. Dourados: Embrapa Agropecuária Oeste. 27 pp. (Boletim de Pesquisa e Desenvolvimento, 20).

Oliveira, O.C.; Oliveira, I.P.; Urquiaga, S.; Alves, B.J.R.; Boddey, R.M. 2004. Chemical and biological indicators of decline/ degradation of Brachiaria pastures in the Brazilian Cerrado. Agriculture, Ecosystems and Environment, 103: 289-300.

Perez, K.S.P., Ramos, M.L.G.; Mcmanus, C. 2004. Carbono da biomassa microbiana em solo cultivado com soja sob diferentes sistemas de manejo no Cerrados. Pesquisa Agropecuária Brasileira, 39: 567-573.

Perin, A.; Santos, R.H.S.; Urquiaga, S.; Guerra, J.G.M.; Cecon, P.R. 2004. Produção de fitomassa, acúmulo de nutrientes e fixação biológica de nitrogênio por adubos verdes em cultivo isolado e consorciado. Pesquisa Agropecuária Brasileira, 39: 35-40.

Reis, A.R.; Furlani Junior, E.; Buzzeti, S.; Andreotti, M. 2006. Diagnóstico da exigência do cafeeiro em nitrogênio pela utilização do medidor portátil de clorofila. Bragantia, 65: 163171.

Ribeiro, J.F.; Walter, B.M.T. 1998. Fitofisionomia do Cerrado. p. 89-166. In: Sano, S.M.; Almeida, S.P. de. (Ed.) Cerrado: ambiente e flora. Embrapa, Brasília, Distrito Federal.

Roscoe, R.; Buurman, P. 2003. Tillage effects on soil organic matter in the density fractions of a Cerrado Oxisol. Soil \& Tillage Research, 70: 107-119.

Santos, L.C.; Antoniolli, Z.I.; Leal, L.T.; Lupatini, M. 2007. População de bactérias e fungos no solo contaminado com cobre nas Minas do Camaquâ, RS, Brasil. Ciência e Natura, 29: $105-114$.

Sedam. 2011. Climatologia do Estado de Rondônia, (http://www. sedam.ro.gov.br/web/guest/Meteorologia/Climatologia). Acesso em 05/03/2011.

Silva, E.E.; Azevedo, P.H.S de; De-Polli. 2007a. Determinação do Carbono da Biomassa Microbiana do solo (BMS-C). Seropédica: Embrapa Agrobiologia. 6 pp. (Comunicado técnico, 98).

Silva, E.E.; Azevedo, P.H.S de; De-Polli. 2007b. Determinação do Nitrogênio da Biomassa Microbiana do solo (BMS-N). Seropédica: Embrapa Agrobiologia. 6 pp. (Comunicado técnico, 96).

Silva, P.C.G. da; Foloni, J.S.S.; Fabris, L.B.; Tiritan, C.S. 2009. Fitomassa e relaçấo $\mathrm{C} / \mathrm{N}$ em consórcios de sorgo e milho com espécies de cobertura. Pesquisa Agropecuária Brasileira, 44 1504-1512. 
Silva, R.R da; Silva, M.L.N.; Cardoso, E.L.; Moreira, F.M. de S.; Curi, N.; Alovisi, A.M.T. 2010. Biomassa e atividade microbiana em solo sob diferentes sistemas de manejo na região fisiográfica campos das vertentes - MG. Revista Brasileira de Ciência do Solo, 34: 1585-1592.

Souza, I.M.Z. de. 2005. Carbono e Nitrogênio da Biomassa do solo em áreas reflorestadas comparadas ao Campo e Mata Nativa no Planalto dos Campos Gerais. 2005. Dissertação de Mestrado, Centro de Ciências Agroveterinárias, Universidade Federal de Santa Catarina, Lages, Santa Catarina. 50 pp.

Sparling, G.P. 1992. Ratio of microbial biomass carbon to soil organic carbon as a sensitive indicator of changes in soil organic matter. Australian Journal of Soil Research, 30: 195-207.

Sparling, G.P.; West, A.W. 1998. A direct extraction method to estimate soil microbial - C - calibration in situ using microbial respiration and ${ }^{14} \mathrm{C}$-labeled cells. Soil Biology \& Biochemistry, Oxford, 20(3): 337-343, 1998.
Tedesco, M.J.; Gianello, C.; Bissani, C.A.; Bohnen, H.; Volkweiss. 1995. Análise de solo, plantas e outros materiais. 2. ed. Porto Alegre: Departamento de solos/UFRGS. 174 pp.

Vance, E.D.; Brookes, P.C; Jenkinson, D.S. 1987. An extraction method for measuring soil microbial biomass-C. Soil Biology \& Biochemistry, 19: 703-707.

Wardle, D.A. 1994. Metodologia para quantificação da biomassa microbiana do solo. 419-436. In: Hungria, M.; Araújo, R.S. (Eds.). Manual de métodos empregados em estudos de microbiologia agricola. Brasília: Embrapa-CNPAF; Embrapa-CNPSo.

Wendling, B.; Jucksch, I.; Mendonça, E.S.; Neves, J.C.L. 2005. Carbono orgânico e estabilidade agregados de um Latossolo Vermelho sob diferentes manejos. Pesquisa Agropecuária Brasileira, 40: 487-494.

Recebido em 10/01/2011

Aceito em 23/07/2011 